\title{
INHALTSVERZEICHNIS
}

Pyrrhos (K.Z.) $\ldots \ldots \ldots \ldots \ldots \ldots \ldots \ldots \ldots \ldots \ldots \ldots \ldots \ldots \ldots$

Marius (W. W.) $\ldots \ldots \ldots \ldots \ldots \ldots \ldots \ldots \ldots \ldots \ldots \ldots \ldots \ldots$

(Vergleichung fehlt)

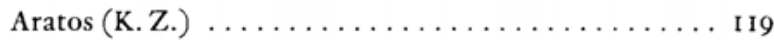

Agis und Kleomenes (K. Z.) $\ldots \ldots \ldots \ldots \ldots \ldots \ldots \ldots$

Tiberius und Gaius Gracchus (W. W.) . . . . . . 237

Vergleichung der Spartaner und der Gracchen . . . 278

Philopoimen (K. Z.) . . . . . . . . . . . . . . . 287

Titus (Flamininus) (W. W.) $\ldots \ldots \ldots \ldots \ldots \ldots \ldots \ldots \ldots \ldots$

Vergleichung des Philopoimen und Titus $\ldots \ldots \ldots 34 \mathrm{I}$

Artoxerxes (K. Z.) . . . . . . . . . . . . . . 347

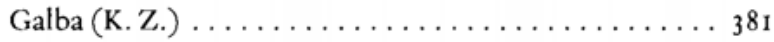

Otho $($ K. Z. $) \ldots \ldots \ldots \ldots \ldots \ldots \ldots \ldots \ldots \ldots, 409$

Erläuterungen $\ldots \ldots \ldots \ldots \ldots \ldots \ldots \ldots \ldots \ldots 429$

Gesamtregister zu Band I-VI

Alphabetisches Verzeichnis der Biographien .... . 452

Griechische Autoren .................. 454

Lateinische Autoren $\ldots \ldots \ldots \ldots \ldots \ldots \ldots 459$

Götter, Menschen, Örtlichkeiten ......... 462

Sachen, Sachbegriffe . . . . . . . . . . . . 603 
PLUTARCH

GROSSE GRIECHEN UND RÖMER

Band 1

Theseus und Romulus - Lykurgos und Numa

Solon und Poplicola $\cdot$ Aristeides und

Marcus Cato

Themistokles und Camillus

Band 2

Kimon und Lucullus - Perikles und Fabius Maximus

Nikias und Crassus · Coriolan und Alkibiades

\section{Band 3}

Lysandros und Sulla $\cdot$ Agesilaos und Pompejus

Pelopidas und Marcellus

\section{Band 4}

Dion und Brutus - Aemilius und Timoleon

Demosthenes und Cicero

Phokion und Cato (der Jüngere)

\section{Band 5}

Alexander und Caesar - Sertorius und Eumenes

Demetrios und Antonius

\section{Band 6}

Pyrrhos und Marius - Aratos

Agis, Kleomenes und die Gracchen

Philopoimen und Titus (Flamininus) · Artoxerxes

Galba und Otho

Namen- und Sachregister 


\section{Wichtige antike Quelle zum Isis-Kult}

PLUTARCH
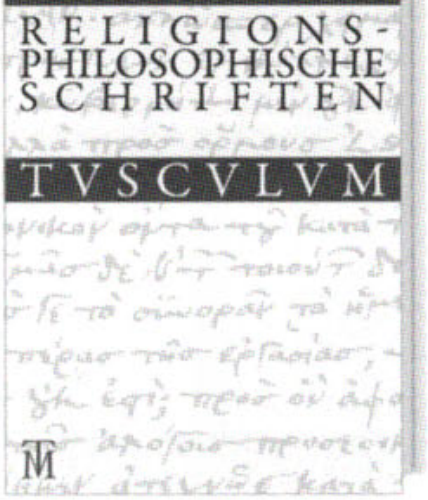

Der vorliegende Band enthält drei Schriften ethischen/religionsphilosophischen Inhalts: "Über Isis und Osiris" ist eine der wenigen und somit wichtigsten antiken Quellen zum Isis-Kult, den römische Legionäre aus Ägypten mitbrachten und im ganzen römischen Reich verbreiteten. „Von der späten Strafe der Gottheit" widmet sich dem religionsgeschichtlich wichtigen Thema der Theodizee. "Vom Aberglauben « nähert sich einem Phänomen, das auch das im ersten Jahrhundert sich ausbreitende Christentum nicht auslöschen konnte.

418 Seiten. ISBN 978-3-538-03524-9

www.artemisundwinkler.de 


\section{Lebenshilfe für Gestresste}

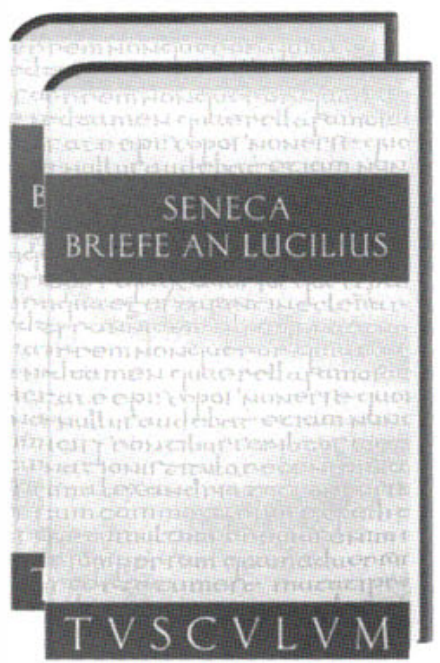

Seneca, als gescheiterter Erzieher des Kaisers Nero berühmt geworden, stammte aus Cordoba. Seine Briefe an Lucilius sind eine Einführung in die Philosophie der Stoiker, deren Ideal es war, durch Gelassenheit und Seelenruhe weise zu werden. Seneca bietet keine systematische Darstellung, sondern zeigt Wege zur philosophischen Bewältigung konkreter Probieme des menschlichen Lebens: Wege zum wahren Glück. Die Briefe sind unmittelbar ansprechend, lebendig dialogisch geschrieben und heute noch aktuell.

Band I: 608 Seiten. ISBN 978-3-538-03501-0

Band II: 664 Seiten. ISBN 978-3-538-03512-6

www.artemisundwinkler.de 
